Palaeoclimatology

\title{
Icy grip on glacial monsoon
}

The Laurentide Ice Sheet sapped the strength of the North American Monsoon during the last ice age but the ice sheet's grip on the monsoon weakened as it retreated northwards.

\section{Sarah E. Metcalfe}

As the major source of summer rainfall in much of Mexico and southwest USA, the North American Monsoon plays a key role in sustaining both natural ecosystems and human activities (Fig. 1). Understanding the drivers of long-term change in this monsoonal system is therefore an important challenge. The state of the North American Monsoon at the Last Glacial Maximum about 21,000 years ago has been debated for more than 30 years. Hypotheses proposed range from little or no change relative to present-day, to complete collapse. Resolving this debate has been challenging due to both varying definitions of the monsoon region ${ }^{1}$ and limitations of the available palaeorecords. Writing in Nature Geoscience, Bhattacharya and co-authors ${ }^{2}$ analyse the isotopic composition of leaf waxes preserved in marine sediment cores to provide insights into long-term changes in the North American Monsoon. They identify the extent of the Laurentide Ice Sheet as the dominant factor controlling monsoon strength during the glacial period. Attempts to attribute long-term changes in moisture availability across the southwest USA to key moisture sources and dynamical controls of the North American Monsoon have produced contradictory results. It remains unclear to what extent summer rainfall persisted at the last glacial maximum and how the balance of summer and winter rain (important today in the region) changed over time. Unfortunately, standard grid-scale global climate models do not have the spatial resolution to capture the full detail of the observed spatial and temporal evolution of the North American Monsoon ${ }^{3}$, limiting their value in exploring this system.

Palaeoclimate archives, such as lake sediments and speleothems, are the principal sources of information about long-term changes in precipitation, but the biggest obstacle to interpreting the information they contain is the need to discriminate between seasons: most records and proxies used cannot separate summer, monsoonal rain from rain that falls in the winter months.

Bhattacharya and colleagues elegantly circumvent this problem by using the hydrogen isotopes in leaf wax biomarkers, preserved in marine sediment cores from offshore Mexico, to reconstruct summer monsoonal rainfall. Although the controls on hydrogen 
isotopes can be complex ${ }^{4}$, measurements are increasingly used in tropical environments to reconstruct changes in precipitation regime. Bhattacharya et al. develop a calibration using a suite of modern sediment core top samples containing leaf waxes. The hydrogen isotope values from different locations are correlated against precipitation observations from climate reanalysis data and a strong positive relationship is found with the proportion of annual rainfall that occurs between July and September. This provides a measure of the annual contribution of summer monsoonal rainfall, but does not allow a quantitative reconstruction of rainfall amount. Application of their calibration to leaf wax biomarker isotopic records from Gulf of California sediment cores reveals a significantly weaker North American Monsoon at the Last Glacial Maximum that contributed around $20-40 \%$ of annual rainfall in the region compared to $50-70 \%$ today.

Bhattacharya et al. argue that the presence of the Laurentide Ice Sheet over much of North America is responsible for the weakened monsoon and propose that the ice sheet forced dry, cold air southwards, reducing the convection driving the monsoon. In their reconstruction, the strength of the North American Monsoon increases in concert with the northward retreat of the Laurentide Ice Sheet as the global climate warmed, supporting the idea that the extent of the Laurentide Ice Sheet was the primary driver of monsoon strength over the last glacial cycle.

Today, and over much of the Holocene, North American monsoon strength is closely linked to Gulf of California sea surface temperatures ${ }^{5}$. Using a sea surface temperature reconstruction ${ }^{6}$ from one of the same cores analysed for hydrogen isotopes, Bhattacharya et al. show that this modern relationship was only established 15,000 years ago, once the Laurentide Ice Sheet had retreated north of $55^{\circ} \mathrm{N}$.

The idea of this switch in monsoon drivers about 15,000 years ago is interesting. Locally, it marks the end of a period of significant warming in the Gulf of California and northern Gulf of Mexico, as well as an abrupt thinning of the Laurentide Ice Sheet ${ }^{7,8}$. Globally, it coincides with the onset of enhanced monsoons elsewhere in the Northern Hemisphere ${ }^{9,10}$. In the North American Monsoon region, the lingering impact of the Laurentide Ice Sheet in the early Holocene apparently delayed the timing of the maximum of this monsoon compared with others globally.

Bhattacharya and co-authors have applied a novel methodology to the reconstruction of summer monsoonal rainfall in a core region of the North American Monsoon and provide a plausible climatological explanation for their results. They suggest that the monsoon persisted even at the Last Glacial Maximum and provide a quantitative estimate of its strength. As the authors note, their interpretation needs further testing, requiring both more sea surface temperature reconstructions from along the western Mexican margin 
and comparison with regional scale climate models better able to capture the range of processes driving the North American Monsoon.

Nonetheless, this work should stimulate a renewed effort to understand the long-term dynamics of this important system. Today, seasonal rainfall across the extended North American Monsoon region exhibit inverse relationships with a number of key large-scale climatic phenomena, such as the Atlantic Multi-decadal Oscillation and the El Niño Southern Oscillation ${ }^{11}$; understanding the monsoon's complex dynamics is not straightforward. There is every reason to suppose that this complexity will continue in the future. More measurements from more palaeoclimatic records are needed to constrain climate models so that they can provide robust future projections for the North American Monsoon region and its growing population ${ }^{12}$.

References

1. Adams, D.K. \& Comrie, A.C. B. Am. Meteorol. Soc. 78, 2197-2213 (1997)

2. Bhattacharya, T., Tierney, J.E., Addison, J.A. \& Murray, J.W. Nat. Geosci. https://doi.org/10.1038/s41561-018-0220-7 (2018).

3. Castro, C.L. et al. J. Clim. 25, 8212-8237 (2012)4. Douglas, P.M.J., Pagani, M., Brenner, M., Hodell, D.A. \& Curtis, J.H. Geochim. Cosmochim. Ac. 97, 24-45 (2012)

5. Barron, J.A., Metcalfe, S.E. \& Addison, J.A. Paleoceanography 27, PA3206, (2012)

6. McClymont, E.L. et al. Paleoceanography 27, PA2202 (2012)

7. Flower, B.P., Hastings, D.W., Hill, H.W. \& Quinn, T.M. Geology 32, 560-597 (2004)

8. Simms, A. et al. Quat. Sci. Rev. 26, 920-940 (2007)

9. Kutzbach, J. et al. Quat. Sci. Rev. 17, 473-506 (1998)

10. Nash, D.J. \& Metcalfe, S.E. Chapter 11 in Quaternary Environmental Change in the Tropics Ch. 11 (John Wiley \& Sons, Chichester, 2012)

11. Méndez, M. \& Magaña, V. J. Clim. 23, 1175-1188 (2010)

12. Maloney, E.D. et al. J. Clim. 27, 2230-2270 (2013)

Sarah E. Metcalfe

School of Geography, University of Nottingham, Nottingham, United Kingdom email: Sarah.Metcalfe@nottingham.ac.uk 


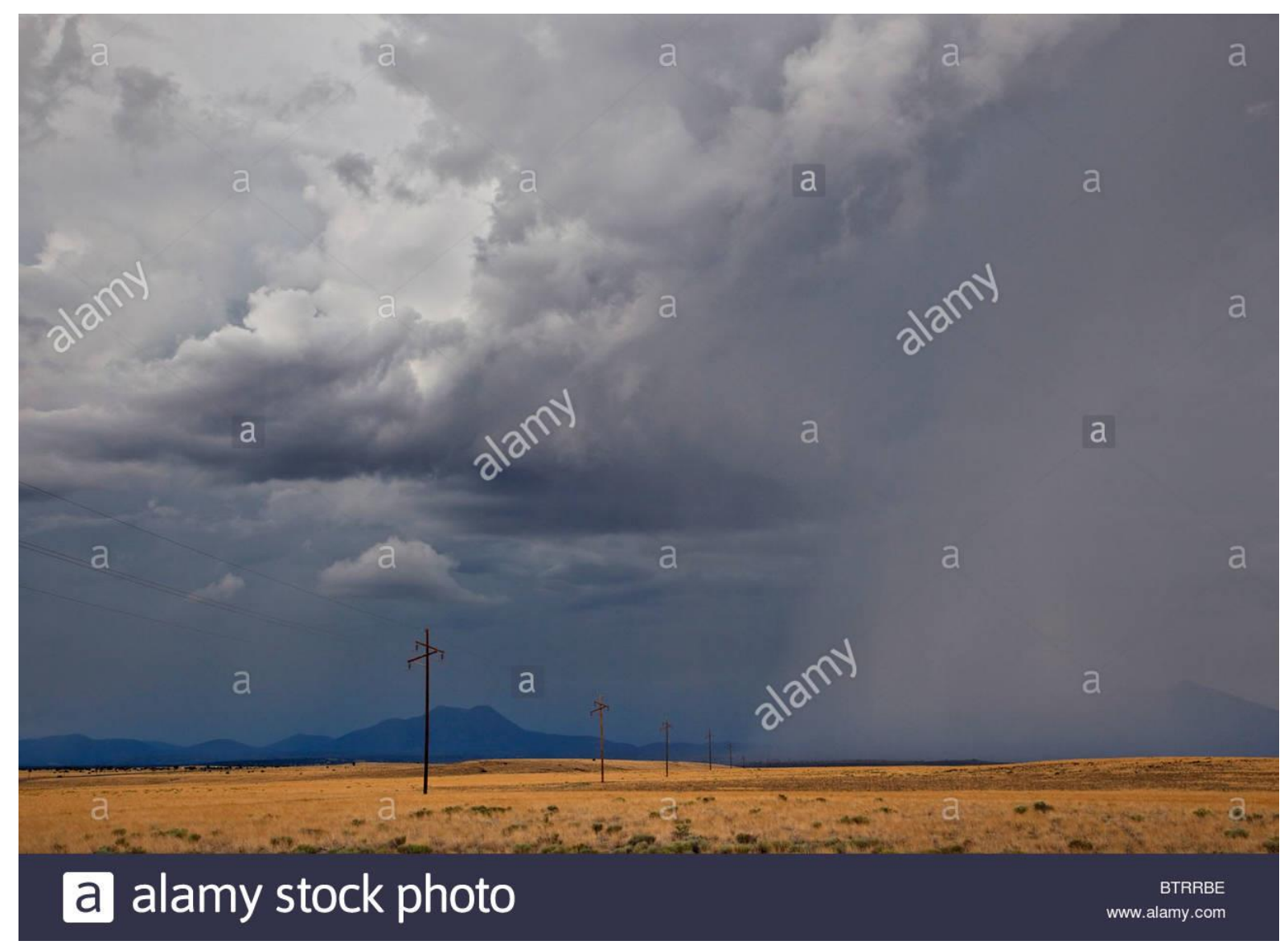

Fig. 1 Summer thunderstorm sweeps across grasslands in Arizona. The North American Monsoon brings vital summer rainfall to large areas of Mexico and south-west USA. Using isotopic analyses of marine sediment cores, Bhattacharya and colleagues ${ }^{2}$ suggest $^{2}$ that during the last glacial period the strength of this system was moderated by the extent of the Laurentide Ice Sheet that once covered much of North America.

Contributor: Tom Bean / Alamy Stock Photo 